\title{
The impact of human resource practices on job satisfaction and intention to stay in emerging economies: Model development and empirical investigation among high caliber governmental employees in Qatar
}

\author{
Ahmed Mehrez ${ }^{\mathrm{a}^{*}}$ and Anas Bakri ${ }^{\mathrm{a}}$
}

${ }^{a}$ College of Business and Economics, Qatar University, Qatar

\begin{tabular}{l}
\hline C H R O N I C L E \\
\hline Article history: \\
Received: October 7, 2018 \\
Received in revised format: No- \\
vember 29, 2018 \\
Accepted: December 14, 2018 \\
Available online: \\
December 14, 2018 \\
\hline Keywords: \\
Human Resource \\
Organizational culture \\
Leadership style \\
Job satisfaction \\
Organizational commitment \\
Intention to stay \\
Job turnover \\
Governmental sectors \\
Qatar
\end{tabular}

\begin{abstract}
High rates in turnover of skilled employees can turn to be a very significant concern in organizations world-wide. Turnover affects productivity, product or service quality and of course profitability. As Human Resources (HR) activities can be considered as a primary source of sustainable competitive advantage in organisations, it would also play a major role in employees' intention to stay or to leave. This paper examines the influence of different human resource practices on employees' job satisfaction and organizational commitment and eventually on job turnover with a focus on the governmental sector in the State of Qatar. In order to develop such investigation, a model was suggested and an online questionnaire was developed and distributed. Hypotheses were tested on a sample of more than 250 highly ranked employees in Qatar. Statistical correlations were conducted to examine the relationships among variables under investigation. The results show that positive relationships were observed between the HR practices under investigation and job satisfaction and organizational commitment which indicate intention to stay.
\end{abstract}

C 2019 by the authors; licensee Growing Science, Canada

\section{Introduction}

The issue of high rate of turnover of skilled employees can turn to be very significant problem in many organisations world-wide. Many researchers consider high rates of turnover as a continual problem (Yin-Fah et al., 2010). Turnover affects productivity, quality and, of course, the profitability. In this manner, academic literature has viewed that human resources (HR) of any firm are potentially the primary source of sustainable competitive advantage (Kochan \& Dyer, 1993; Pfeffer, 1994; Sarwara et al., 2013). Moreover, turnover also is very costly for any organization in terms of attracting and finding skilled employees with required experience, training these employees, and of course cost related to replacing these employees if they decide to quit. Understanding reasons and factors that are associated with leaving/staying in an organization is of great importance as it provides employer with information on how to design strategies that can reduce turnover rates.

\footnotetext{
* Corresponding author.

E-mail address: ahmed.mehrez@qu.edu.qa (A. Mehrez)

(C) 2019 by the authors; licensee Growing Science, Canada doi: $10.5267 /$ j.msl.2018.12.007
} 
Researchers argue that reasons of turnover in organisations may vary (Samuel \& Chipunza, 2009; Ovadje, 2009), however, most of these reasons are related either to work conditions and/or different human resource practices like compensations and benefits, employee services, training and development, performance management and job security (Ton \& Huckman, 2008). According to Wilson (2000) employee turnover may reach crisis rates in these organisations that do its best to keep its staffing level from an international labour market. In this manner, multinational environment can turn to be a challenge in maintaining work force. Recruiting internationally can cause higher cost for organisations in terms of the time needed to complete recruiting process, money spent on such process and even in training required for these employees to start working properly. Therefore, retaining these employees is of great importance for such organisations.

According to Khilji and Wang (2006), HR professionals; especially in developing countries and emerging economies, may not explore reasons and factors associated with high rates of turnover and thus develop strategies to overcome. The primary objective of this study is to explore the effect of various HR practices on employees' intention for job satisfaction and organizational commitment (Fabra \& Camisón, 2008). This exploration is to be accomplished in Qatari governmental sector and within high calibre employees. While an expansion in all areas of life in Qatar, there is an increasing need to develop its public sector in order to reach its objectives. The development of the public sector is an essential part of Qatari's 2030 national vision. This vision includes institutional and organizational capacity building, efficient and transparent delivery of public services, fruitful public-private cooperation and partnerships. In order to achieve such objective, human capabilities should be attracted, trained and maintained. Public sector leaders are considered of high importance in order to shape organisational strategies and draw its future. All in all, employee turnover is costly for many reasons; firstly, organisations will lose their valuable employees. Secondly, the high cost that comes from advertisement for new positions, recruitment process and the termination process (Abbasi \& Hollman, 2008). Thirdly, it is always regrettable and costly when employees leave an organisation. Thus, it is always of great importance for organisational managers, researchers and academics to deeply analyse more on this issue in a way to better understand and then control (Ton \& Huckman, 2008). In essence, the main objective of this research is to examine effects of different HR practices on intention to stay decision in the governmental sector in an emerging economy. In other words, this research questions how HR practices may affect employees' decisions to stay or to quit their jobs.

\subsection{Significance of the study}

The huge interest of the governmental sector in building a strong image in any society can push countries forward. Therefore, there is an increasing need to ensure the maximum use of human resources. However, high rates of turnover among employees of the government due to strong completion from private sector may turn to be a crucial problem. This research offers a detailed insight into how HR practices might influence job satisfaction and organizational commitment and eventually influence employee retention. A significant tool to enable decision makers and managers to adopt strategies that prevent employee turnover and thus avoid many related costs would be useful, in particular, at a time when the government needs its key employees to achieve countries' national visions. In addition and despite the multiple researches on such important area of study, there is no one comprehensive model suggested to examine HR practices influencing on employees' turnover. This aim of this research is to fill this gap in research by developing, after comprehensively reviewing different HR practices affecting retention, a model that examines such relationship. The aim of this research will even go beyond this by empirically use this model within the high calibre governmental employees in Qatar.

\subsection{Research question}

This paper focuses on the following main research question:

How would different HR practices influence job satisfaction and organizational commitment and ultimately influence employees' intention to stay in Qatari's governmental sector? 


\section{Literature review and model development}

\subsection{The concept of turnover}

Employee turnover is a not only a concern for HR professionals, but also for all managers and decision makers of any organization due to its major effects on organisational sustainability (Ton \& Huckman, 2008). Basically, human resources are the most vital and essential among all organizational resources; however, HR is also the most difficult resource to control (Szamosi, 2006; Rodriguez Perez \& Ordóñez de Pablos, 2003). Turnover was defined by Mobley (1982, p.10) as "the cessation of membership in an organization by an individual who received monetary compensation from the organization". Nevertheless, authors distinguish between "turnover" and "turnover intention". Basically, the "turnover" refers to the actual quit behaviour, when the employees move to another organization leaving his/her current workplace (Price, 2001). 'Turnover intention' refers to the employees' intention to quit and the probability for an employee of leaving his/her current workplace (Cotton \& Tuttle, 1986).

Employee turnover has become a major issue for many originations worldwide. Hence employee turnover can be a major loss and human resources management in organizations always must try to prevent it by applying effective retention strategies (James \& Mathew, 2012). Too rapid turnover can lead to financial and non-financial unpleasant consequences. It can seriously affect quality, profitability and productivity of the firms with different sizes (Iqbal, 2010). Fitz-enz (1997) stated that the average companies may lose about $\$ 1$ million by losing 10 key managerial skills and added that external effects would affect customers and sales (Fitz-enz, 1997). James and Mathews (2012) emphasized that replacing employees lead to costs such as inducting, training and developing new employees. Moreover, retention strategies have an impact on the intention of employees to stay with and not to leave the organization. According to Ramlall (2001) "the concept of human capital is that people possess skills, experience and knowledge, and therefore these have economic value to organizations. These skills, knowledge and experience represent capital because they enhance productivity". Many HR practices were suggested to examine employees' intention to stay in organization (Joarder \& Sharif 2011; Grace $\&$ Khalsa, 2003; Cotton \& Tuttle, 1986). Despite different focus and even results, authors agreed on the influence of HR practices on employees' intention to leave a job.

\subsection{Human Resource practices and turnover drivers}

There are many strategies associated with retaining employees and improving their job satisfaction, organizational commitment and, in turn, their long-term relationship with their employers. For an organization to be the best in its marketplace, it should be able to retain the best talent available (Chatterjee, 2009). Walker (2001) identified 7 factors that may affect employee retention: (1) compensation and benefits, (2) challenging work, (3) opportunity to learn and be promoted, (4) organizational atmosphere, (5) good relationships with others, (6) good balance between personal and professional life, (7) good communication channels. Others such as Hytter (2007) found that factors such as leadership style, rewards system, training and development, career development opportunities, physical working conditions and balance between personal \& professional life have an indirect influence on employee retention (Kyndt et al., 2009). Many authors then suggest that different HR practices may affect employees' turnover decision in different manner. Many HR practices could be considered as drivers for employees to stay or to leave an organization. However, many argue that these HR drivers may not be directly linked to job retention unless moderated by job satisfaction and organizational commitment. Following are different views toward drivers for retention:

\subsection{Compensation and benefits and turnover}

It is notable that many researchers argue that compensation and benefits given to employees are; if not, the most identifier in determining employees' job satisfaction, which in turn affects turnover intention (Joarder \& Sharif, 2011; Grace \& Khalsa, 2003; Cotton \& Tuttle, 1986). In accordance, Ovadje (2009) concluded a strong relationship between compensations and benefits and the turnover intention. However, Khatri et al. (2001) found that pay has insignificant influence on turnover intentions and decisions 
to quit. In the same manner. Many researchers then have suggested that the reward and recognition system can be a tool to increase work motivation and job satisfaction (Özlen \& Hasanspahic, 2013). Employee dissatisfaction with pay, for instance, can decrease commitment to the job, increase stealing, and catalyse turnover. Money is a major determinant factor for employees when they consider leaving or staying in an organisation. According to Herzberg's theory, salary is listed as one of the hygiene factors that cause dissatisfaction and is indeed the first one. In addition, one of the important reasons for employees to leave their job is unequal or low pay structures. These are some of the main causes of employee dissatisfaction which can drive employees to leave their job (Loncar \& Singh, 2010). According to Ramlall (2001) "Strategic rewards play a significant role in attraction and retention by providing a framework for engagement, communication, education, and reinforcement for all employees". Hence, a firm's pay philosophy should support its mission and culture and should be tied to performance. According to equity theory, employees are concerned not only over the absolute amount of reward that they receive but also with what others receive. They compare such outcomes as salary level, compensations and recognitions to input such as effort, education, experience, and so on. One of the assumptions based on this theory is that if employees perceive what they get as unequal then they will take what action they see as appropriate. One of these actions is to quit the job and look for another employer (Ramlall, 2004). As a matter of fact, salary and compensations play a significant role in affecting job satisfaction and indeed employee retention.

\subsection{Employees' services and turnover}

Some others concentrated on employee services as a determinant of intention to quit/stay in a certain job. Lucero and Allen (1994) and Frye and Breaugh (2004) argue that employee benefits, such as health insurance plan, air tickets to employee and family members, retirement plan or even financial assistance programs would act as important reasons to stay in a job or quit it. This may occur as the availability of employee services and facilities would enhance the level of attachment to an organization (Baughman et al., 2003; Kopelman et al., 2006; Thompson \& Prottas, 2006).

Additionally, studies show that employees prefer working for organisations that recognise the importance of family responsibilities by avoiding unnecessary increased work stress (Kopelman et al., 2006; Thompson \& Prottas, 2006). Studies show that many of working parents with children ought to leave their jobs because of the lack of organisational support towards their families (Estes \& Glass, 1996). This is why Rothausen et al. (1998) figured out that having an on-site childcare facility may lead to more satisfied employees and result in higher retention rates.

\subsection{Salary dispersion and turnover}

In addition, one other reason studied as a potential cause to quit a job is salary dispersion. As it is common that employees will compare their benefits with others either internally or from outside the organization. Fair and competitive compensation system in general is one of essential strategies to retain and keep employees in any organization. On the same track, Pfeffer (1994) argued that any individual who feel disadvantage in a system with unequal rewards will simply leave the organization.

\subsection{Manager's support and turnover}

Another HR practice has been examined by researchers as a possible mean to quit a job which is supervisor and manager support. Many studies show a positive relationship between such support and turnover intention and organizational commitment (Rhoades et al., 2001). Despite variance in perceiving this kind of support (Maertz et al., 2007), but most studies have drastically linked managerial support with employee turnover (Rhoades et al., 2001; Maertz et al., 2007). 
Leadership and managerial support can be considered as important keys when they come to employees' intention to leave or stay in any organization. According to (Mills, 2008), "people do not quit organizations; they quit leaders". So it is important for managers to adopt a suitable leadership style to increase employee satisfaction. Leadership is more about giving control than taking it. Leaders who can encourage employees to collaborate, take the initiative, become accountable, and who can empower and inspire them to lead in their turn, belong to the type of leader who can create successful organizations. Employees want to feel embedded and as if they belonged to an organization that they work for; they want some freedom and to have their importance recognized by the system that they are part of. According to Barbuto and Burback (2006) "Leaders with empathetic qualities inspire greater depth of self-exploration in employees and increase job satisfaction, morale and positive perception in others". Senior leaders influence employees' overall satisfaction, productivity and commitment to the organization. According to Saniewski (2011) "according to a 2002 Watson Wyatt study, dissatisfaction with management and conflicts with managers were two of the top five reasons employees left the organization". Therefor leadership is an essential factor in retaining employees (Saliba, 2007; Zhang et al., 2012).

\subsection{Training and development and turnover}

Another main HR practice studied as a possible reason for turnover is training and development which is considered as one of the most important functions of any HR practice (Joarder et al., 2011). The basic consensus after these studies is that the company which utilises and improves its process of the training and development would have a competitive advantage over other organizations and employees working inside it will be more satisfied and have less intention to quit their jobs (Schuler \& MacMillan, 1984; Joarder et al., 2011). This is to be accomplished through increasing employees' commitment by building a long term relationship with their organisations through training (Samuel \& Chipunza, 2009). This is why Grace and Khalsa (2003) concluded that training and development can be acknowledged as one of the most vital causes controlling employees' turnover decision. It appears that there is not significant relationship between training provided to employees and turnover.

In accordance, Kaye \& Jordan-Evans (2003) argued that the top three reasons for an employee to stay with an organization are career planning, growth and learning opportunities (Saliba, 2007). Moreover, according to Kyndt et al. (2009) "researchers confirm that effective training and opportunities to learn and develop enhance employee retention". The argument that can be made is that if the employer can show the importance of the employee to the organization by investing in his/her training and development, then it earns that employee's commitment in return. Lack of training \& systematic approaches to development, lack of assessment of the result of such systems and lack of commitment to employees' long-term development programmes can cause employees to lose commitment and eventually employee turnover. Additionally, a tuition assistant could be a kind of personal development provided to employees by employers. Employees who are given a tuition assistant are more likely to stay with the organization, which makes the tuition reimbursement an important factor in gaining employees' commitment and loyalty (Ramlall, 2001). According to Iqbal (2010), employees who have few opportunities for professional or personal improvement are more likely to quit their current jobs and search for an employer who provides better growth and learning opportunities. Furthermore, according to Kyndt et al. (2009) "there is a relationship between organizational commitment and various learning processes". In conclusion, researchers and studies indicate that opportunities for training and development affect organizational commitment as well as employee retention.

\subsection{Performance appraisal and turnover}

Another important HR practice is performance appraisal which represents an important metric to organizational behaviour (Dulebohn \& Ferris, 1999). As agreed among researchers, performance appraisal would be useful in order to assist poor performance as well as the awards for good performance. 
This is why Stewart et al. (2007) argue that there is a strong relationship between job performance and intentions to quit. In accordance, job performance-turnover relationship has been demonstrated empirically in numerous primary studies and positive relationships were examined.

\subsection{Employee empowerment and turnover}

Some other studies also have focused on high-performance work practices that influence employees' motivation to have high-performance in the workplace like. As employees with high performance work practices appear to be more embedded in their jobs, such employees are expected to have low levels of intentions to leave the organization and vice versa. High-involvement work practices describe a wide group of approaches for organizing, deploying, and utilizing human resources. Although there is no one unified agreement concerning what is, and is not, a high-involvement practice, many human resources management scholars suggest these practices probably include such approaches as, employee suggestion or complaint systems, incentive based, self-managing work teams, job enlargement and job enrichment redesign, employee attitude surveys, and quality improvement teams.

\subsection{Working conditions and turnover}

Safe working condition may also directly be connected to the quality of employees work achievements (Kramer \& Schmalenberg, 2008). The main consensus is that healthier working conditions would result in less rates of employees' turnover. In the same context, Pejtersen and Kristensen (2009) suggested that healthy working conditions will reduce employee stress and also will lead to more motivated workforce as well as long-run organizational efficiency, and lower employee turnover. However, McKay and Avery (2005) indicated that recruitment of minority groups into a workplace may ironically contribute to high early turnover if they raise expectations for a positive diversity climate that is not fulfilled. In general, studies suggest that any change in the working conditions perceptions may have greater impact on turnover decisions when workplaces are perceived to be good in comparison to when workplaces are perceived to be bad (Simons \& Jankowski, 2008).

Azanzaa \& Fernando (2013) stated that, the flexibility-oriented culture is the best culture for supporting employees and leadership processes. Such culture usually supports innovation, development and openness to new idea. Many researchers also assert that a positive organizational culture is the one which values individuals' contributions, gives opportunities to learn and takes initiatives, supports innovation, creativity and growth and empowers employees (Ghorbanhosseini, 2013). Such a culture is expected to enhance employees' job satisfaction, organizational commitment and employee morale and thus will ultimately determine the success of the organization. In contrast, culture that implements practices such as focusing on system rather than people, adopting change only when it must and inhibiting learning and innovation will lead to a negative climate, low staff morale and increased turnover (Saliba, 2007). Thus, it can be said that organizational culture is a key factor associated with job satisfaction, organizational commitment and of course employee retention.

\subsection{Job security and turnover}

One other HR practice studied for relationship to turnover is Job security. Early Herzberg (1968) argues that job security is the degree to which the organization provides constant employment to the employees. Delery and Doty (1996) believe that job security is the degree to which an employee could expect to stay in a certain job. Job security has been identified as one of the most important factor of human resources practices (Pfeffer, 1994) which indicates organization's commitment to their workforce and so inspires employees to exchange their obligation by showing joint commitment to the organization. Therefore, job security is one of the major components in determining employee's commitment to an organization (Hom \& Griffeth, 1995) which influence employee's retention intention (Samuel \& Chipunza, 2009). 


\subsection{Job design and analysis and job retention}

According to Ramlall (2001) "Job analysis is the procedure through which the duties of the respective positions and the characteristics of the potential incumbents are determined". According to the job design motivation theory, the task itself is a key factor in motivating employees. Boring jobs can reduce the motivation to perform well while challenging ones can do the opposite. Variety, autonomy, and decision authority, job enrichment and job rotation can be some ways of adding variety and challenge to jobs (Ramlall, 2004). Factors such as not providing a realistic job preview for a position may lead to employee turnover (Ramlall, 2001). Conversely, designing jobs in a certain way can be a retention tool to encourage employees not to leave an organization.

\subsection{Job satisfaction, organizational commitment and job retention}

Job satisfaction attracts the interest of many researchers due to its influence on many essential aspects such as productivity, efficiency, turnover rate and intention to quit (Yang et al., 2008). Many studies show that there is a relationship between job satisfaction, organizational commitment and turnover or employees intention to stay with or to leave an organization (Addae \& Parboteeah, 2006). According to Lambert and Paoline (2010) employees who are dissatisfied or not committed to their job are more likely to quit it voluntarily. Moreover, many experts, managers and researchers believe that job satisfaction may influence work productivity, employee commitment, employee turnover and employee retention. Most studies have treated job satisfaction as an independent variable but organizational commitment as a dependent variable. Job satisfaction may be related to or a response to a specific job related issue while organizational commitment is more consistent over time and ensues as a result of job satisfaction (Eslami \& Gharakhani, 2012). Worrell (2004) noted that an employee's job satisfaction level can be influenced by intrinsic and extrinsic job factors. The intrinsic factors are based on personal perceptions and internal feelings such as recognition, advancement, and responsibility. In contrast, extrinsic factors are external job related factors such as salary, supervision and job conditions. Studies show that both extrinsic and intrinsic factors have a significant influence on job satisfaction. In addition, James and Mathew (2012) stated that employee satisfaction or dissatisfaction can be a reason to leave or stay with an organization and can arise from different personal factors such as compensation $\&$ benefits, job security, autonomy, supervision and related issues or relationship with colleagues, etc.. Therefore, job satisfaction can be considered as a significant factor that affects job retention.

Job Satisfaction can be described as, the individual's reaction to his or her job situation, and this could be either positive or negative. Ellickson and Logsdon (2002) confirmed that utilitarian causes are organization-oriented, and will lead also to the following potential benefits: increase productivity, increase in organizational commitment, lower absenteeism, lower turnover, and increased organizational effectiveness. Ellickson and Logsdon (2002) also argued that employees who are satisfied with their job may do extra mile and engage in organizational citizenship behaviours, which sometimes involves going beyond the call of duty. For example, stay after his working hours, work at home or even come in his days off without an extra pay (Wagner, 2007). Conversely, dissatisfied employees may increase counterproductive behaviours, such as burnout, withdrawal, and workplace aggression. Job satisfaction has been always found to be related to employee turnover in relevant literature; and accordingly unsatisfied employees change jobs to get away from their situation (Dole \& Schroeder, 2001). Ellickson and Logsdon (2002) illustrated two major antecedent variables of job satisfaction to be present in most cases, irrespective of the theoretical approach used in a study. The two variables were cited as environmental factors, and personal attributes or characteristics. Examples of environmental factors are pay, promotional opportunity, and other factors that are closely associated with the job itself or the work environment. Personal attributes and characteristics were categorized as the second general antecedent variable, and may also be classified as demographic in nature. 


\subsection{Organizational commitment, job satisfaction and job retention}

Organizational commitment has a consistent relationship to turnover; highly committed employees are more likely to stay longer with their employers. Some research finds a direct relationship between organizational commitment and turnover and some states that, if the relationship is indirect it may affect the intention to leave or stay (Wagner, 2007). Moreover, employees with high commitment to the organization are those who appreciate the membership within it and value its objectives; these are more likely to remain in it and work hard on its behalf (Kyndt et al., 2009). So organizational commitment could be important in determining factors that would affect employee retention.

\section{Conceptual Model}

Many turnover drivers then are researched and linked to job retention. While this study is confirmatory in nature, a proposed model is suggested to answer the latent research question. This model is built on the basis of findings from previous studies. A comprehensive review of literature indicates that ten main drivers related to HR can play a significant role in employees' intention to leave or to stay in a certain organisation. However, this link may not be direct and could be moderated by two other variables; job satisfaction and organizational commitment. Fig. 1 presents this conceptual framework which illustrates the relationships among study variables.

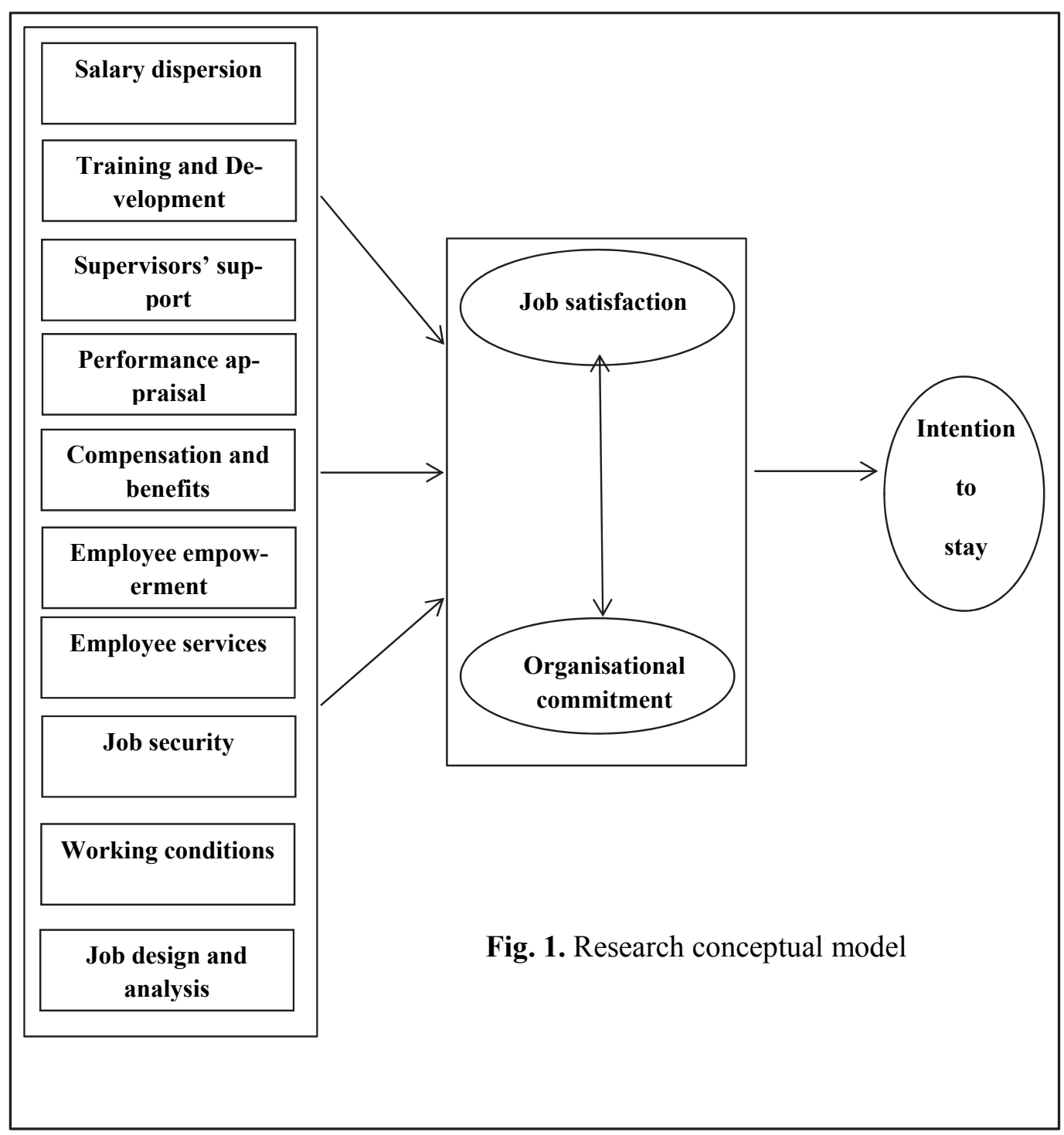


Fig. 1 shows that turnover drivers are: Salary dispersion, training and development, supervisor's support, performance appraisal, compensation and benefits, employee empowerment, employee services, job security, working conditions and job design would affect job satisfaction and organizational commitment. It is also notable that there is a relationship between job satisfaction and organizational commitment. In turn, job satisfaction and organizational commitment would affect employees' intention to stay in an organization.

In essence, research hypotheses can be developed as follows:

- RH1: There is a mutual positive relationship between job satisfaction and organizational commitment.

- $\quad$ RH2: There is a positive relationship between job satisfaction and job retention.

- RH3: There is a positive relationship between organizational commitment and job retention.

- RH4: There is a positive relationship between HR practices and organizational commitment.

- RH4-1: There is a positive relationship between compensation and benefits and organizational commitment.

- RH4-2: There is a positive relationship between employees'services and organizational commitment.

○ RH4-3: There is a positive relationship between salary dispersion and organizational commitment.

- RH4-4: There is a positive relationship between Manager's support and organizational commitment.

- RH4-5: There is a positive relationship between training and development and organizational commitment.

- RH4-6: There is a positive relationship between performance appraisal and organizational commitment.

- RH4-7: There is a positive relationship between employee empowerment and organizational commitment.

- RH4-8: There is a positive relationship between job security and organizational commitment.

- RH4-9: There is a positive relationship between working conditions and organizational commitment.

○ RH4-10: There is a positive relationship between job design and organizational commitment.

- RH5: There is a positive relationship between HR practices and job satisfaction.

- RH5-1: There is a positive relationship between compensation and benefits and job satisfaction.

- RH5-2: There is a positive relationship between employees' services and job satisfaction.

- RH5-3: There is a positive relationship between salary dispersion and organizational commitment.

- RH5-4: There is a positive relationship between Manager's support and job satisfaction.

- RH5-5: There is a positive relationship between training and development and job satisfaction.

- RH5-6: There is a positive relationship between performance appraisal and job satisfaction.

- RH5-7: There is a positive relationship between employee empowerment and job satisfaction.

- RH5-8: There is a positive relationship between job security and job satisfaction.

- RH5-9: There is a positive relationship between working conditions and job satisfaction.

- RH5-10: There is a positive relationship between job design and job satisfaction. 


\section{Research Methodology}

\subsection{Development of research instrument}

Data were collected by using a questionnaire. This questionnaire collected data on 14 measures, as follows:

1. Demographics

2. Job satisfaction

3. Organizational Commitment

4. Management support

5. Working conditions
6. Training and development

7. Job design and analysis

8. Compensations and benefits

9. Intention to stay in the current job

10. Employees services
11. Salary dispersion

12. Performance appraisal

13. Employee empowerment

14. Job security

As such a model has never been investigated before; each part in this questionnaire has been adopted from a certain source. The first section requested various types of demographic information, including gender, age, job level, workplace classification, educational level, experience, and nationality. The scale for job satisfaction that was adopted was the scale of generic job satisfaction by Macdonald and Maclntyre (1997). This scale consists of 10 questions that measures employee satisfaction. For organizational commitment, the scale that was used was the scale developed by Meyer and Allen (1991): the 8-point continuous commitment scale. Management support was measured by using the 13-item range of leadership behaviour by Harris and Ogbonna (2001), which assumes three leadership styles (participative, supportive and directive). To measure working conditions, a 24-item OCI scale by Wallach (1983) was adopted. This scale assumes that the culture of an organization can be classified as innovative, supportive or bureaucratic. A 4-item scale was adapted so as to measure the training and development opportunity provided by the employer on a 5-point Likert-type scale ranging from (1) 'strongly disagree' to (5) 'strongly agree'. Job design and analysis was measured by using the instrument developed by Weiss et al. (1967). This instrument measures the job autonomy, task \& skills variety, task significance and feedback from the job. Respondents show their agreement to both questions on 5points scale ranging from (1) strongly disagree to (5) strongly agrees. 7-items scale was adapted to measure the compensation and benefits provided by the employer on 5-points scale ranging from (1) strongly disagrees to (5) strongly agree. Intention to stay was measured by using the instrument developed Morgeson and Humphrey (2006). This instrument measures the respondent intention to leave or stay in the current job. Respondents show their agreement to both questions on 5-points scale ranging from (1) strongly disagree to (5) strongly agrees. In addition, participants were requested to give a weight to the factors from 7 (for the highest factor that might strengthen their intention of leaving their job) to 1 (the least effective factor in this regard). In order to measure internal consistency among instrument questions and variables, Cronbach's Alpha was measured for all variables suggested in this study. Table 1 indicates results that Cronbach's Alpha values are considered consistent for this study where the lowest Alpha is 0.732 and the highest is 0.962 .

\section{Table 1}

Cronbach's Alpha for instrument variables

\begin{tabular}{lccc}
\hline Research variable & Cronbach's Alpha & Research variable & Cronbach's Alpha \\
\hline Job satisfaction & 0.886 & Intention to Stay & 0.775 \\
Organisational commitment & 0.880 & Employee Services & 0.856 \\
Management support & 0.962 & Salary dispersion & 0.913 \\
Working conditions & 0.957 & Performance appraisal & 0.732 \\
Training and Development & 0.809 & Employee empowerment & 0.812 \\
Job Design and Analysis & 0.838 & Job security & 0.829 \\
Compensation and Benefits & 0.926 & & \\
\hline
\end{tabular}

\subsection{Sample and Data Collection}

This self-administered questionnaire was distributed to all governmental institutions working in Qatar. These companies were assigned based on data from the General Secretariat of Development Planning 
and Cabinet departments. Only high ranked employees were sent email invitation through monkey.com in order to fill in the questionnaire in the month of October 2015. In two weeks duration, a reminder was sent to the whole population which is close to 1200 highly ranked employees. After another couple of weeks, the questionnaire was closed. The total number of valid respondents was 287 with a percentage of $25 \%$. This response rate is considered suitable for analysis and can give indications on links among research variables.

\subsection{Statistical Procedure and data analysis}

The data were cleaned by SPSS software, which was also used to analyse such the features of the data. Structural Equation Modelling and Coefficient Correlations were used to test hypotheses and to answer the latent research question.

\subsection{Sample Population Profile}

The valid responses to the survey totalled 287. As illustrated in the Table 2, most of respondents were female (52\% females and $48 \%$ males). $87 \%$ of the respondents were Qataris, the rest not. $17 \%$ of the respondents had a high school degree, $62 \%$ had a bachelor's degree and $21 \%$ were postgraduates. Additionally, $18 \%$ of the respondents were younger than 26 but most were in the age groups $26-30$ or 31 35 , i.e. $32 \%$ and $30 \%$ respectively. $17 \%$ of the respondents fell into the age group $36-45 ; 2 \%$ of them fell into the age group $46-55$ and $1 \%$ were older than $55.11 \%$ of the respondents had less than 1 year in their current job, $45 \%$ had been for $1-5$ years in their current jobs, $29 \%$ had been for $6-10$ years, $7 \%$ had been for $11-15$ years and $8 \%$ had been there for more than 15 years.

Table 2

Summary of Demographic Variables

\begin{tabular}{|c|c|c|}
\hline Variable & Frequency & Percentage \\
\hline \multicolumn{3}{|l|}{ Gender: } \\
\hline Male & 48 & 48 \\
\hline Female & 52 & 52 \\
\hline \multicolumn{3}{|l|}{ Nationality } \\
\hline Qatari & 87 & 87 \\
\hline Non-Qatari & 13 & 13 \\
\hline \multicolumn{3}{|l|}{ Education Level } \\
\hline High School Degree & 17 & 17 \\
\hline Bachelor Degree & 62 & 62 \\
\hline Postgraduate Degree & 21 & 21 \\
\hline \multicolumn{3}{|l|}{ Age } \\
\hline Less than 26 & 18 & 18 \\
\hline $26-30$ & 32 & 32 \\
\hline $31-35$ & 30 & 30 \\
\hline $36-45$ & 17 & 17 \\
\hline $46-55$ & 2 & 2 \\
\hline Above 55 & 1 & 1 \\
\hline \multicolumn{3}{|c|}{ Years of service in the current jobs } \\
\hline Less than one year & 11 & 11 \\
\hline Between 1 and 5 years & 45 & 45 \\
\hline Between 6 and 10 years & 29 & 29 \\
\hline Between 11 and 15 years & 7 & 7 \\
\hline More than 15 years & 8 & 8 \\
\hline
\end{tabular}

\section{Results and Hypotheses Testing}

In order to test the suggested relationships among variables posted in Fig. 1, structural equation modelling (SEM) method was used. As proposed (Gerbing \& Anderson, 1988), the SEM method would be benefit in order to assess how different variables could be related to each other. In such manner, construct validity was initiated followed by an evaluation of links among variables. Additionally, a preliminary Pearson Correlations technique was used so that making sure of variables possible relationships. 


\subsection{Construct validity}

In order to determine the construct validity of the suggested research model, two main steps were suggested; un-dimensionality analysis and reliability analysis (O'Leary-Kelly \& Vokurka, 1998). The main objective of this un-dimensionality is to make sure that a level of satisfaction could be gained out of two determined variables (O'Leary-Kelly \& Vokurka, 1998). Validity would be accepted in case of a significant association among suggested variables under study. In this research, the un-dimensionality analysis took place based on a principal component analysis for each of the dependent variables. The results of these principal component analyses indicated that relationships could be suggested among such variables. This is why the un-dimensionality test was confirmed positive. Followed, a reliability analysis was done in order to make sure that model variables are reliable. In order to proceed with this reliability analysis, Joreskog's rho of internal consistency (Jöreskog et al., 1999) was used. In addition, the convergent validity analysis was tested based on Fornell and Larcker's (1981) approach (Table 3).

Table 3

Reliability and convergent validity analysis

\begin{tabular}{lcc}
\hline & Jöreskog's $\rho$ & Rho of convergent validity \\
\hline Compensation and Benefits & 0.89 & 0.65 \\
Managerial support & 0.84 & 0.60 \\
Working conditions & 0.88 & 0.71 \\
Training and Development & 0.85 & 0.62 \\
Job design and Analysis & 0.90 & 0.71 \\
Employee Services & 0.87 & 0.62 \\
Salary dispersion & 0.91 & 0.72 \\
Performance appraisal & 0.84 & 0.60 \\
Employee empowerment & 0.82 & 0.58 \\
Job security & 0.82 & 0.59 \\
Job satisfaction & 0.86 & 0.61 \\
Organisational Commitment & 0.87 & 0.62 \\
\hline
\end{tabular}

It can be concluded then from Table 3 that there is a satisfactory standard of reliability for each of the model variables. All the rho coefficients values are greater than 0.80 (Fornell \& Larker, 1981) which is considered satisfactory.

\subsection{Hypotheses testing}

In order to test hypotheses, casual relationships were tested using Pearson Correlations. Pearson's correlation coefficient $\mathrm{r}$ is often used to describe relation between two random variables $\mathrm{X}$ and $\mathrm{Y}$ (Kreinovich et al., 2013). A Pearson's correlation test was used to test the test hypotheses in this research (Table 4 and Fig. 2).

\section{Table 4}

Pearson correlations among research variables

\begin{tabular}{lccc}
\hline & Job Satisfaction & Organisational Commitment & Intention to stay \\
\hline Compensation and Benefits & 0.598 & 0.553 & 0.725 \\
Managerial support & 0.754 & 0.462 \\
Working conditions & 0.571 & 0.791 & 0.298 \\
Training and Development & 0.762 & 0.398 & 0.882 \\
Job design and Analysis & 0.401 & 0.611 & 0.493 \\
Employee Services & 0.502 & 0.322 & 0.658 \\
Salary dispersion & 0.891 & 0.604 & 0.725 \\
Performance appraisal & 0.661 & \\
Employee empowerment & 0.521 & & \\
Job security & 0.491 & & \\
Job satisfaction & 0.604 & & \\
Organisational Commitment & &
\end{tabular}

The correlation value; which is always referred to as Pearson's product-moment $r$ or $r$ coefficient, requires both a magnitude and a direction of either positive or negative. The range of the $r$ value is 
usually from -1 to 0 to +1 ; the minus sign explains a negative relationship whereas the increase in one variable will lead to a decrease in another variable while a positive sign shows that the variables are moving together. If the correlation value is zero, then no relationship exists between the variables. It is not as easy to interpret the value of Pearson's' correlation as it is to interpret other scales. However it could be roughly described as follows: results smaller than or equal to 0.35 are generally considered to represent low or weak correlations, 0.36 to 0.67 modest or moderate correlations, and 0.68 to 1.0 strong or high correlations with $\mathrm{r}$ coefficients greater than or equal to 0.90 judged very high correlations (Taylor, 1990). In referring to this, Fig. 2 shows that RH1 which states that there is a mutual positive relationship between job satisfaction and organizational commitment; the correlation as shown is 0.604 which is considered a moderately positive correlation, signifying that RH1 is accepted.

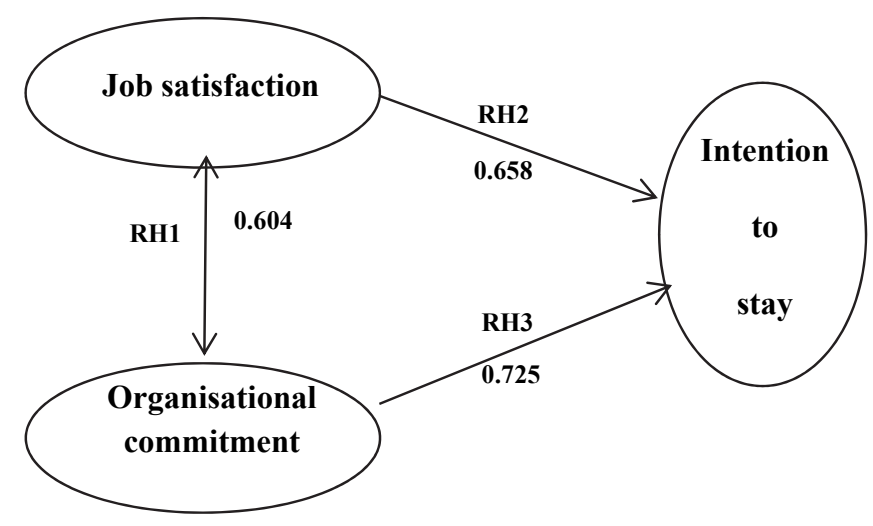

Fig. 2. Research hypothesis 1, 2 and 3

Fig. 2 indicates also that RH2 states that there is a positive relationship between job satisfaction and job retention. The job retention is measured by the intention to stay or leave the current organization. The correlation is 0.658 which is considered a moderately positive correlation and this means the RH2 can be accepted. In the same manner, RH3 claims that there is a positive relationship between organizational commitment and job retention. The job retention as an option is measured by the intention to stay or leave the current organization. The correlation as showed in table 4 is 0.725 , which is considered a strong positive correlation and this indicates that RH3 is accepted.

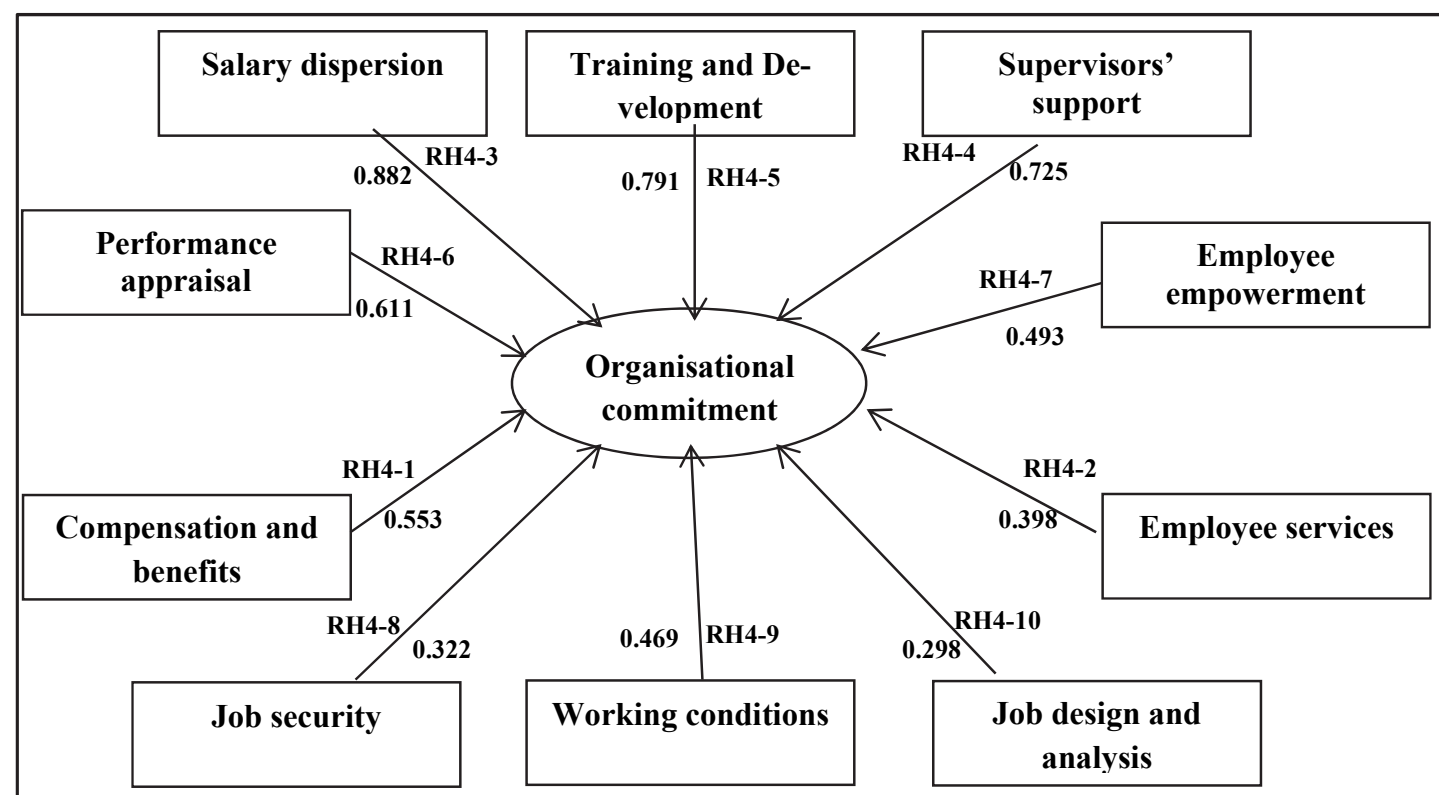

Fig. 3. Research hypothesis 4 
Fig. 3 indicates that RH 4 which claims that there is a positive relationship between HR practices and organizational commitment. $10 \mathrm{HR}$ practices were suggested in this research model. According to results of Pearson Correlations from Table 4, these practices do affect organizational commitment and positive correlations are statistically confirmed. However, effects of these practices range from moderate to weak as follows: the most important HR practice affecting organizational commitment is salary dispersion followed by training and development, managerial support, performance appraisal, compensation and benefits, employee empowerment. The least effect HR practices are: job analysis and design, working conditions, and employee services.

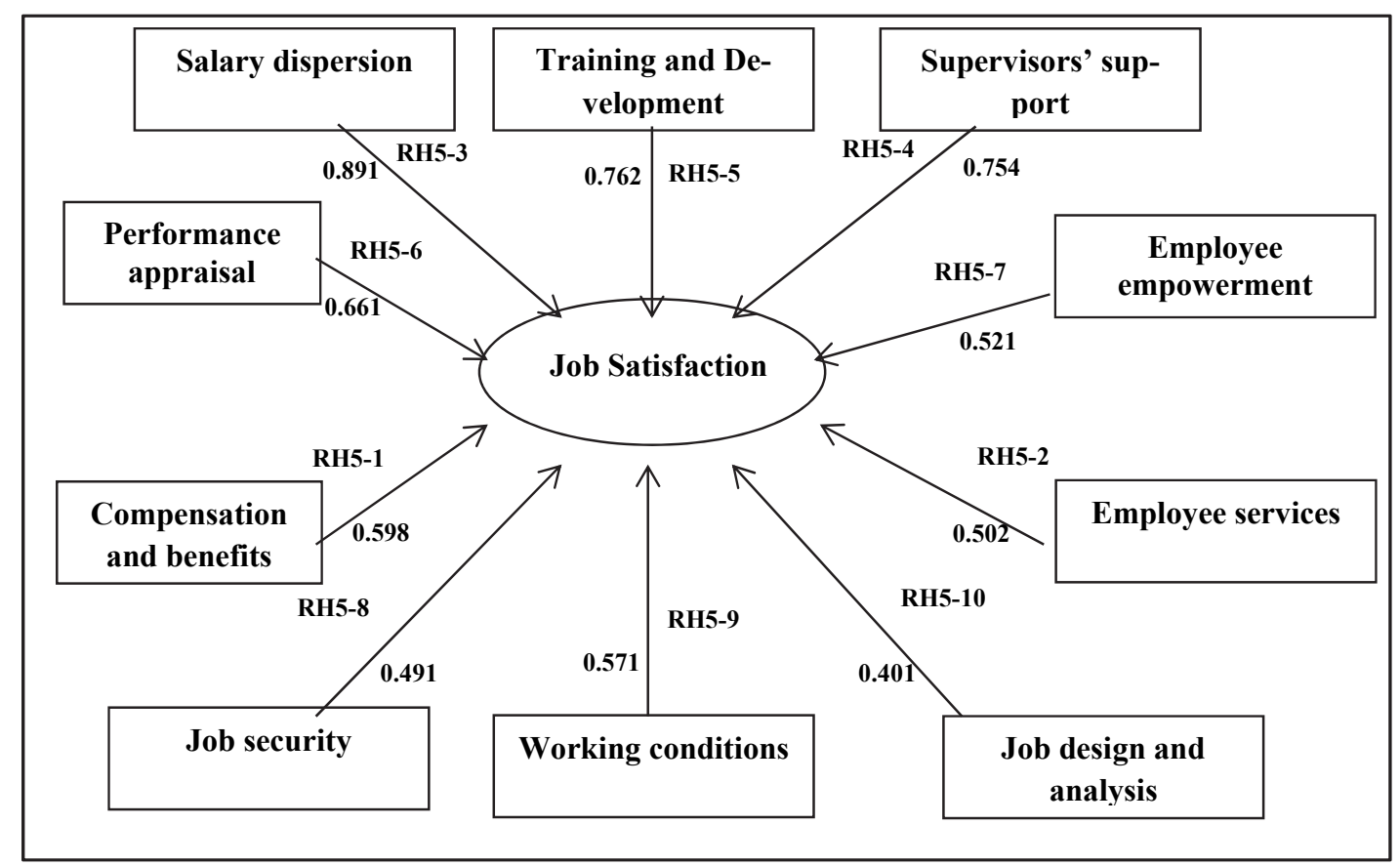

Fig. 4. Research hypothesis 5

As previously indicated, RH 5 states that there is a positive relationship between HR practices and job satisfaction (Fig. 4). $10 \mathrm{HR}$ practices were suggested in this research model. According to results of Pearson Correlations from Table 4, these practices do affect job satisfaction and positive correlations are statistically significant. However, effects of these practices range from moderate to weak as follows: the most important HR practice affecting job satisfaction is salary dispersion followed by training and development, managerial support, performance appraisal, compensation and benefits, employee empowerment. The least effect HR practices are: job analysis and design, working conditions, and employee services. In general, it may be argued that strength of correlation varied for all research hypotheses from weak, moderate to strong. This would lead to an acceptance to all hypotheses. However, Pearson product-moment correlation does not take into consideration whether a variable has been classified as a dependent or independent variable. It treats all variables equally, which can be a limitation of this test.

\section{Discussion and Conclusion}

The main purpose of this study was to measure the relationship between assigned retention strategies including: Compensation and benefits, managerial support, working conditions, training and development, job analysis and design, employee services, salary dispersion, performance appraisal, employee empowerment, and job security on intention to stay or to quit a certain job moderating job satisfaction and organizational commitment. After a comprehensive review of literature that showed that there are positive relationships among these practices and dependent variables, a model was developed and 
tested. In general, statistical Pearson's correlation results showed that positive moderate to strong correlation are valid among the aforementioned variables. These results cope with other studies as it is reported in the literature that job satisfaction and organizational commitment positively influences the intention to stay or to leave an organization. The present study has found that job satisfaction was positively correlated with organizational commitment and that both variables are positively correlated to employees' turnover intention. This means that employees who are satisfied about their jobs have a high degree of commitment and do not intend to leave their jobs. It is also reported in the literature that compensations and benefits, supportive culture and supportive leadership influence job satisfaction. The present study finds that these three variables are also positively correlated to job satisfaction. So it may be said that a good compensations and benefits policy, a supportive culture and supportive leadership can increase employees' satisfaction. Moreover, the literature mentioned that elements such as a supportive culture, supportive leadership and strategies such as good training and development opportunities are capable of increasing employees' commitment to their jobs. The present study shows that this hypothesis can be accepted and that the correlation between these variables and the organizational commitment is positive and strong. Furthermore, according to previous studies, job analysis and design and good training and development opportunities positively influence employees' intention to stay in an organization. Pearson's correlation shows a positive moderate to strong relationship between these two variables and such an intention.

\section{Limitations, scope and future research}

This study has some limitations that should be mentioned. First, the sample size: although the sample size was adequate for the number of variables, larger samples would enhance the validity of this study more and more. Second, the target of this study was mainly highly ranked employees in the Qatari governmental sector, but repeating the study to include all other different non-governmental organizations in Qatar would also enhance the validity and generalizability of results. Third, data in this research was collected at a single point in time. However, this approach might not be useful if the reasons behind relationships among variables were sought. Using longitudinal studies can overcome this weakness by collecting data over a longer period. Fourth, a piloting questionnaire was not conducted to evaluate the scale competency. A forward-backward translation method from English to Arabic and then from Arabic back to English caused some difficulties participants. Another important limitation of this study is the length of the questionnaire, which had the effect of making respondents bored and tired by the end so there is a possibility that they either submitted the survey without completing it or they gave less attention to the later survey questions. A pilot study would, of course, have shown this possibility and prompted remedial action. Future research could examine the influence of more retention strategies such as communication channels, flexibility of working hours and/or such demographic influences as gender, age, educational level...etc. Motivation theories also such as need theory, expectancy theory, equity theory and a job design model could be taken into consideration in a similar study, since they are often emphasized as having a significant influence on employee retention. In addition, a future study might also be conducted to cover all other sectors in Qatar such as oil and gas companies, the health and education sectors, the army and the police...etc. Another possible future study could look into the influence of Qatar's labour laws on the retention and turnover of Qatari and non-Qatari employees, because the law puts no restriction on Qataris to change their jobs at any time. It is not known how this could affect the HR decisions of employers.

\section{References}

Abbasi, S. M., Hollman, K. W., \& Hayes, R. D. (2008). Bad bosses and how not to be one. Information Management Journal-Prairie Village, 42(1), 52.

Addae, H. M., \& Parboteeah, K. P. (2006). Organizational Information, Organizational Commitment and Intention to Quit. International Journal of Cross Cultural Management, 6(3), 343-359.

Azanzaa, G., \& Fernando , J. A. (2013). Authentic leadership and organizational culture as drivers of employees' job satisfaction. Journal of Work and Organizational Psychology, 29(2), 45-50.

Barbuto, J. E., \& Burbach, M. E. (2006). The emotional intelligence of transformational leaders: A field study of elected officials. The Journal of social psychology, 146(1), 51-64. 
Baughman, R., DiNardi, D., \& Holtz-Eakin, D. (2003). Productivity and wage effects of "family-friendly" fringe benefits. International Journal of Manpower, 24(3), 247-259.

Berson, Y., Oreg, S., \& Dvir, T. (2008). CEO values, organizational culture and firm outcomes. Journal of Organizational Behavior, 29(5), 615-633.

Chatterjee, N. (2009). Study of organisational culture and its effect on employee retention. ASBM Journal of Management.

Cotton, J. L., \& Tuttle, J. M. (1986). Employee turnover: A meta-analysis and review with implications for research. Academy of Management Review, 11(1), 55-70.

Delery, J. E., \& Doty, D. H. (1996). Modes of theorizing in strategic human resource management: Tests of universalistic, contingency, and configurational performance predictions. Academy of management Journal, 39(4), 802835.

Dole, C., \& Schroeder, R. G. (2001). The impact of various factors on the personality, job satisfaction and turnover intentions of professional accountants. Managerial auditing journal, 16(4), 234-245.

Dulebohn, J. H., \& Ferris, G. R. (1999). The role of influence tactics in perceptions of performance evaluations' fairness. Academy of Management Journal, 42(3), 288-303.

Ellickson, M. C., \& Logsdon, K. (2002). Determinants of job satisfaction of municipal government employees. Public Personnel Management, 31(3), 343-358.

Eslami, J., \& Gharakhani, D. (2012). Organizational Commitment and Job Satisfaction. ARPN Journal of Science and Technology, 2(2), 85-91.

Estes, S. B., \& Glass, J. L. (1996). Job changes following childbirth: Are women trading compensation for familyresponsive work conditions?. Work and Occupations, 23(4), 405-436.

Fabra, M. E., \& Camisón, C. (2008). Direct and indirect effects of education on job satisfaction: A structural equation model for the Spanish case. Economics of Education Review, 28(5), 600-610.

Fitz-enz, J. (1997). It's Costly to Lose Good Employees. Workforce, 76(8), 50-52.

Fornell, C., \& Larcker, D.F. (1981). Evaluating structural equations models with unobservable variables and measurement error. Journal of Marketing Research, 18(1), 39-50.

Frye, N. K., \& Breaugh, J. A. (2004). Family-friendly policies, supervisor support, work-family conflict, familywork conflict, and satisfaction: A test of a conceptual model. Journal of Business and Psychology, 19(2), 197220.

Gerbing, D.W., \& Anderson, J.C. (1988). An updated paradigm for scale development incorporating unidimensionality and its assessment. Journal of Marketing Research 25(2), 186-192.

Ghorbanhosseini, M. (2013). The effect of organizational culture, teamwork and organizational development on organizational commitment: the mediating role of human capital. Tehnički vjesnik, 20(6), 1019-1025.

Grace, D. H., \& Khalsa, S. A. (2003). Re-recruiting faculty and staff: The antidote to today's high attrition. Independent School, 62(3), 20-27.

Harris, L. C., \& Ogbonna, E. (2001). Leadership style and market orientation: an empirical study. European journal of marketing, 35(5/6), 744-764.

Herzberg, F. (1968). One more time: How do you motivate employees.

Hom, P. W., \& Griffeth, R. W. (1995). Employee turnover. South-Western Pub.

Hytter, A. (2007). Retention strategies in France and Sweden. Irish Journal of Management, 28(1).

International Energy Agency (IEA) (2011), World energy Outlook. France, www.iea.org.

Iqbal, A. (2010). Employee Turnover: Causes, Consequences and Retention Strategies in the Saudi Organizations. The Business Review, Cambridge, 16(2), 275-281.

James, L., \& Mathew, L. (2012). Employee Retention Strategies: IT Sector. SCMS Journal of Indian Management, 79.

Joarder, M. H., Sharif, M. Y., \& Ahmmed, K. (2011). Mediating Role of Affective Commitment in HRM Practices and Turnover Intention Relationship: A Study in a Developing Context. Business \& Economics Research Journal, 2(4).

Jöreskog, K.G., Sörbom, D., Du Toit, S., \& Du Toit, M. (1999). LISREL 8: New statistical features. Scientific Software International Inc, Chicago, IL.

Kaye, B., \& Jordan-Evans, S. (2003). How to retain high-performance employees. Annul-San Diego-Pfeiffer and Company, 2, 291-298.

Khilji, S. E., \& Wang, X. (2006). 'Intended'and 'implemented'HRM: the missing linchpin in strategic human resource management research. The International Journal of Human Resource Management, 17(7), 1171-1189.

Kochan, T. A., \& Dyer, L. (1993). Managing transformational change: the role of human resource professionals. International Journal of Human Resource Management, 4(3), 569-590.

Kramer, M., \& Schmalenberg, C. (2008). Confirmation of a healthy work environment. Critical Care Nurse, 28(2), $56-63$. 
Kreinovich, V., Nguyen, H. T., \& Wu, B. (2013). Towards a Localized Version of Pearson. International Journal of Intelligent Technologies and Applied Statistics, 6(3), 215-224.

Kopelman, S., Rosette, A. S., \& Thompson, L. (2006). The three faces of Eve: Strategic displays of positive, negative, and neutral emotions in negotiations. Organizational Behavior and Human Decision Processes, 99(1), 81-101.

Kyndt , E., Dochy, F., Michielsen, M., \& Moeyaert, B. (2009). Employee Retention: Organisational and Personal Perspectives. Vocations and Learning, 2(3), 195-215.

Lambert, E., \& Paoline III, E. A. (2010). Take this job and shove it: An exploratory study of turnover intent among jail staff. Journal of Criminal Justice, 38(2), 139-148.

Levoy , B. (2010, April 1). Improve staff retention with employee referrals. Retrieved October 5, 2014, from Veterinary Economics: http://veterinarybusiness.dvm360.com/improve-staff-retention-with-employee-referrals

Loncar, N., \& Singh, P. (2010). Pay satisfaction, job satisfaction and turnover intent. Relations Industrielles / Industrial Relations, 65(3), 470-490.

Lucero, M. A., \& Allen, R. E. (1994). Employee benefits: A growing source of psychological contract violations. Human Resource Management, 33(3), 425-446.

Macdonald, S., \& Maclntyre, P. (1997). The generic job satisfaction scale: Scale development and its correlates. Employee Assistance Quarterly, 13(2), 1-16.

Maertz Jr, C. P., Griffeth, R. W., Campbell, N. S., \& Allen, D. G. (2007). The effects of perceived organizational support and perceived supervisor support on employee turnover. Journal of Organizational Behavior: The International Journal of Industrial, Occupational and Organizational Psychology and Behavior, 28(8), 1059-1075.

Meyer, J. P., \& Allen, N. J. (1991). A three-component conceptualization of organizational commitment. Human resource management review, 1(1), 61-89.

McKay, P. F., \& Avery, D. R. (2005). Warning! Diversity recruitment could backfire. Journal of Management Inquiry, 14(4), 330-336.

Mills, G. E. (2008). TRANSFORMATIONAL LEADERSHIP AND EMPLOYEE RETENTION: AN EXPLORATORY INVESTIGATION OF THE FOUR CHARACTERISTICS. ProQuest.

Morgeson, F. P., \& Humphrey, S. E. (2006). The Work Design Questionnaire (WDQ): developing and validating a comprehensive measure for assessing job design and the nature of work. Journal of applied psychology, 91(6), 1321.

Mobley, W. H. (1982). Employee turnover: Causes, consequences, and control. Addison-Wesley.

Mustapha, N., Ahmad, A., Uli, J., \& Idris, K. (2010). Job characteristics as antecedents of intention to stay and mediating effects of work family facilitation and family satisfaction among single mothers in Malaysia. International Journal of Business and Social Science, 1(3), 59-74.

Mustapha, N., Ahmad, A., Uli, J., \& Iis, K. (2010). Job characteristics as antecedents of intention to stay and mediating effects of work family facilitation and family satisfaction among single mothers in Malaysia. International Journal of Business and Social Science, 1(3), 59-74.

N.A. (2013). Economic Development. Retrieved 12 28, 2014, from Ministry of Planining and Statstics: http://www.gsdp.gov.qa/portal/page/portal/gsdp_en/qatar_national_vision/Economic_development

N.A. (n.d.). Government and Legislatives. Retrieved 12, 13, 2014, from Hukoomi: http://portal.www.gov.qa/wps/portal/about-qatar/GovernmentLegislatives/!ut/p/a1/hZFbb9sgFIB_Sx_M04IxvoROQhNxc2vdV13XNPNLBTYjjmyTAMHav59TZom7YJ0JM4537mHZbgPy577RnHX6J63k15mb9t1nq-fk2yLPrEcbei3U3x IgRiUfg8wigvzyG hf GpbfkQxdY3ZPkpePxYKMyCZNH9Y4RknyE hHid

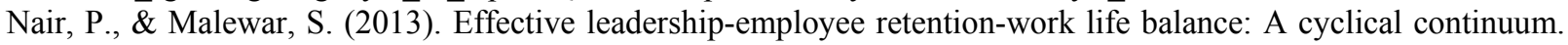 IOSR Journal of Business and Management, 10(3), 80-86.

O'Leary-Kelly, S. W., \& Vokurka, R. J. (1998). The empirical assessment of construct validity. Journal of Operations Management, 16(4), 387-405.

Ovadje, F. (2009). Exploring turnover among middle managers in a non-western context. International Journal of Business Research, 10(2), 64-80.

Özlen, M. K., \& Hasanspahic, F. (2013). A descriptive study on the motivation of Bosnian workers. International Journal of Academic Research in Business and Social Sciences, 3(7), 184.

Qatar olympic committee. (2011). Retrieved NOV 1, 2014, from qatar olympic committee: http://www.olympic.qa/en/AboutQOC/Pages/QOC-Values.aspx

Pejtersen, J. H., \& Kristensen, T. S. (2009). The development of the psychosocial work environment in Denmark from 1997 to 2005. Scandinavian Journal of Work, Environment \& Health, 284-293.

Pfeffer, J. (1994). Managing with power: Politics and influence in organizations. Harvard Business Press.

Price, J. L. (2001). Reflections on the determinants of voluntary turnover. International Journal of Manpower, 22(7), 600-624.

Rai, G. (2013). Impact of organizational justice on satisfaction, commitment and turnover intention:Can fair treatment by organizations make a difference in their workers' attitudes and behaviors? International Journal of Human Scienes, 10(2), 260-284. 
Ramlall, S. (2004). A review of employee motivation theories and their implications for employee retention within organizations. Journal of American Academy of Business, 5(1/2), 52-63.

Ramlall, S. J. (2001). An Analysis of Employee Retention Practices within a Large Complex Organization. Bell \& Howell Information and Learning Company.

Rhoades, L., Eisenberger, R., \& Armeli, S. (2001). Affective commitment to the organization: The contribution of perceived organizational support. Journal of Applied Psychology, 86(5), 825.

Rodriguez Perez, J., \& Ordóñez de Pablos, P. (2003). Knowledge management and organizational competitiveness: a framework for human capital analysis. Journal of Knowledge Management, 7(3), 82-91.

Rondeau, K. V., \& Wagar, T. H. (2006). Nurse and resident satisfaction in magnet long-term care organizations: do high involvement approaches matter?. Journal of Nursing Management, 14(3), 244-250.

Rothausen, T. J., Gonzalez, J. A., Clarke, N. E., \& O'DELL, L. L. (1998). Family-friendly backlash-fact or fiction? The case of organization on-site child care centers. Personnel Psychology, 51(3), 685-706.

Saliba, S. (2007). Organizational strategies that inspire and improve employee retention and morale. Canada: Royal Roads University.

Samuel, M. O., \& Chipunza, C. (2009). Employee retention and turnover: Using motivational variables as a panacea. African Journal of Business Management, 3(9), 410-415.

Saniewski, L. L. (2011). The impact of leadership on employee retention. (Doctoral dissertation, UNIVERSITY OF PHOENIX).

Sarwara, S. Z., Mirzaa, E., Ehsana, N., Khan, K., \& Hanif, H. (2013). Determining the impact of age and LOS on job satisfaction: a case study of Pakistan automotive industry. The International Journal of Human Resource Management, 24(2), 415-435.

Schuler, R. S., \& MacMillan, I. C. (1984). Gaining competitive advantage through human resource management practices. Human Resource Management, 23(3), 241-255.

Simons, K. V., \& Jankowski, T. B. (2007). Factors influencing nursing home social workers' intentions to quit employment. Administration in Social Work, 32(1), 5-21.

Sports Investment . (n.d.). Retrieved nov 1, 2014, from aspire4sport: http://www.aspire4sport.com/single.php?pageName=Sports\%20Investment

Stewart, G. L., Darnold, T. C., Zimmerman, R. D., Parks, L., \& Dustin, S. L. (2010). Exploring how response distortion of personality measures affects individuals. Personality and Individual Differences, 49(6), 622-628.

Szamosi, L. T. (2006). Just what are tomorrow's SME employees looking for?. Education + Training, 48(8/9), 654665.

Taylor, R. (1990). Interpretation of the correlation coefficient: a basic review. Journal of diagnostic medical sonography, 6(1), 35-39.

Thompson, C. A., \& Prottas, D. J. (2006). Relationships among organizational family support, job autonomy, perceived control, and employee well-being. Journal of occupational health psychology, 11(1), 100.

Ton, Z., \& Huckman, R. S. (2008). Managing the impact of employee turnover on performance: The role of process conformance. Organization Science, 19(1), 56-68.

Wagner, C. (2007). Organizational commitment as a predictor variable in nursing turnover research: literature review. Journal of Advanced Nursing, 60(3), 235-247.

Walker, J. W. (2001). Zero defections? Human Resource Planning, 24(1), 6-8.

Weiss, D. J., Dawis, R. V., \& England, G. W. (1967). Manual for the Minnesota Satisfaction Questionnaire. Minnesota studies in vocational rehabilitation.

Wilson, C. N., Stranahan, H., \& Mitrick, J. M. (2000). Organizational characteristics associated with hospital CEO turnover/Practitioner application. Journal of Healthcare Management, 45(6), 395.

Worrell, T. (2004). School Psychologists' Job Satisfaction: Ten Years Later. (Doctoral dissertation, Virginia Polytechnic Institute and State University).

Yang, H., Miao, D., Zhu, X., Sun, Y., Liu, X., \& Wu, S. (2008). The influence of a pay increase on job satisfaction: A study with the Chinese army. Social Behavior and Personality: an international journal, 36(10), 1333-1340.

Yin-Fah, B. C., Foon, Y. S., Chee-Leong, L., \& Osman, S. (2010). An exploratory study on turnover intention among private sector employees. International Journal of Business and Management, 5(8), 57.

Zhang, M., Fried, D., \& Griffeth, R. (2012). A review of job embeddedness: Conceptual, measurement issues, and directions for future research. Human Resource Management Review, 22(3), 220-231.

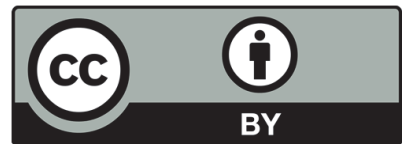

(C) 2019 by the authors; licensee Growing Science, Canada. This is an open access article distributed under the terms and conditions of the Creative Commons Attribution (CC-BY) license (http://creativecommons.org/licenses/by/4.0/). 